\title{
3 - WOODY VEGETATION AND ITS USE DURING THE NEOLITHIC AT THE TREE SHELTER
}

\author{
Elena Marinova \\ Katholieke Universiteit Leuven
}

The site of Tree Shelter gives the rare possibility to get an idea on the Neolithic vegetation and its use by humans during their visits to the Red Sea Mountains, Egypt, an area still poorly studied from an archaeobotanical point of view. The main source of archaeobotanical information for this study, are wood charcoals from the Neolithic layers of the site (Archaeological Horizons (AH) 1-4). Additional plant macrofossil material from several ovicaprine coprolites was analysed. In an earlier publication (Moeyersons et al. 1999) identifications were provided from two wood charcoal samples from the two lowermost levels AH4 and AH5. They were no longer available for the present analysis because they have been submitted for ${ }^{14} \mathrm{C}$ dating.

The site is located in a tributary wadi of the wadi Sodmein at Gebel Umm Hammad, Red Sea Mountains. The detailed climatic and environmental conditions of the site are described in Vermeersch et al. (chapter "Physical environmental context ", this book).

The modern arboreal vegetation of the Tree Shelter wadi is limited to a lonely Acacia tree at the entrance of the wadi. The modern vegetation in the broad area of the Red Sea coastal land between wadi Qena and the Nubian desert (lat. $26^{\circ}-24^{\circ} \mathrm{N}$ ) is described by Kassas and Girgis (1970) and Zahran and Willis (1990). As for the non-arboreal vegetation of the Tree Shelter wadi and the Sodmein wadi no archaeobotanical record is available, the main considerations of the modern plant cover concern the tree formations, especially in the wadis - the main plant habitat in the surrounding of the site. Generally associations of Acacia raddiana, A. tortilis and A. ehrenbergiana represent the principal vegetation in the main wadis today. There are also associations of Salvadora persica, Leptadenia pyrotechnica, with more limited distribution are communities of Balanites aegyptiaca. In wadis with higher groundwater table Tamarixcommunities occur. Wadis are subject to extensive grazing because they contain vegetation that is richer than in other types of desert habitat and they are easily accessible for herders and their domestic animals. This lead in the beginning of the $20^{\text {th }}$ century and especially after active cutting of the perennial vegetation in the 50-60ties to overexploitation and partly extinction of the tree vegetation in the area (Hobbs 1989).

The site was mostly not permanent, connected with hunting activities and represents Epipaleolithic and Neolithic occupation in the area (Vermeersch et al.2002). This is of major importance for the interpretation of the found wood charcoal assemblages.

\section{1 - Method and materials}

The wood charcoal material studied originates generally from hearths, but also outside occasionally from stray finds and was collected by hand picking from visible concentrations. This sampling strategy was dictated by the poor preservation conditions of the site. The laboratory study was carried out on manually broken charcoal $(>2 \mathrm{~mm}$ ) in three anatomical plains (transversal, tangential and radial) with reflected light microscope. Identification literature (Fahn et al.1986, Neuman 1989, Neumann et al, 2001) was used in combination with the reference collection of modern wood housed at the Laboratory of Archaeobotany of Africa, University of Frankfurt. The counts of charcoal fragments were presented as percentage ratios from the total number of charcoals studied per archaeological horizon (fig. 59). Additional to this an estimation of the frequency (in \%) of the main found taxa in the samples of AH 1-3 was made (fig. 60).

During the interpretation of the results it was necessary to take into account the large variation within the different archaeological horizons (respectively occupation phases) in the available number of wood charcoal fragments and samples (fig. 59, "total number of charcoal pieces studies" and "total number of the samples"). Because of the morphological resemblance of the various species, the identifications of Acacian wood are indicated as "Acacia-type". In the area under consideration the most probable Acacia-species according to the distributions mentioned in Kassas and Girgis (1970) are Acacia tortilis, Acacia raddiana 
Table 19 - Results of the wood charcoal analysis of the site Tree Shelter - absolute number of the found wood charcoal fragments.

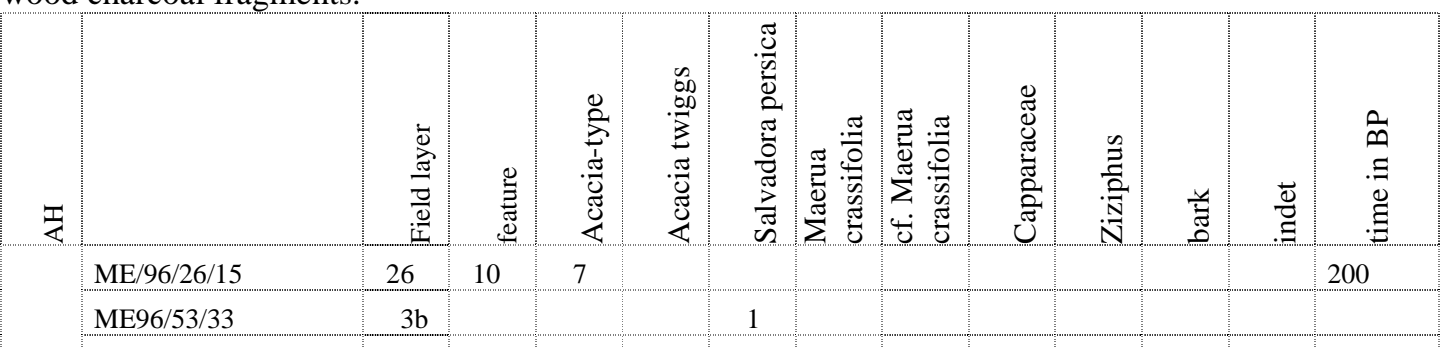

\begin{tabular}{|c|c|c|}
\hline \multirow{5}{*}{1} & ME/96/53/41 & 3 \\
\hline & ME/96/53/47 & 3 \\
\hline & ME96/53/55 & 3 \\
\hline & ME/96/53/56 & $3 \mathrm{~b}$ \\
\hline & total & \\
\hline \multirow{5}{*}{$1-2$} & ME/96/11/20 & 27 \\
\hline & $\mathrm{ME} / 96 / 11 / 79$ & 27 \\
\hline & ME96/12/5 & 28 \\
\hline & $\mathrm{ME} / 17 / 9$ & 35 \\
\hline & total & \\
\hline \multirow{7}{*}{2} & ME/96/54/2 & 4 \\
\hline & ME/96/59/102 & $8 b$ \\
\hline & $\mathrm{ME} / 96 / 59 / 154$ & $8 \mathrm{~b}$ \\
\hline & $\mathrm{ME} / 96 / 59 / 379$ & $8 \mathrm{~b}$ \\
\hline & $\mathrm{ME} / 96 / 60 / 99$ & 9 \\
\hline & $\mathrm{ME} / 96 / 60 / 75$ & 9 \\
\hline & ME/96/60/119 & 9 \\
\hline & ME/96/60/122 & 9 \\
\hline
\end{tabular}

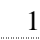

11

\begin{tabular}{|l|l|l|}
\hline & $\mathrm{ME} / 96 / 55 / 43$ & 5 \\
\hline 2-3 & 5 \\
\hline $\mathrm{ME} / 96 / 55 / 70$ & 5 \\
\hline $\mathrm{ME} 96 / 55 / 123$ & \\
\hline total &
\end{tabular}

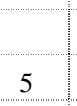

total

\begin{tabular}{|c|c|}
\hline ME/96/59/386 & $8 b$ \\
\hline $\mathrm{ME} / 96 / 14 / 2$ & 23 \\
\hline \multicolumn{2}{|l|}{ ME/96/59/38 } \\
\hline $\mathrm{ME} / 96 / 10 / 35$ & $20 a$ \\
\hline \multicolumn{2}{|l|}{$\mathrm{ME} / 96 / 52 / 357$} \\
\hline $\mathrm{ME} / 52 / 357$ & 9 \\
\hline ME/96/52/357 & 2 \\
\hline ME/96/59/356 & $8 b$ \\
\hline ME/96/59/365 & $8 b$ \\
\hline ME/96/59/379 & $8 b$ \\
\hline ME/96/59/38 & $8 b$ \\
\hline ME/96/60/614 & 9 \\
\hline ME/96/59/387 & $8 b$ \\
\hline ME/96/60/358 & 9 \\
\hline $\mathrm{ME} / 96 / 60 / 485$ & 9 \\
\hline $\mathrm{ME} / 96 / 10 / 35$ & $20 a$ \\
\hline $\mathrm{ME} / 96 / 60 / 121$ & \\
\hline total & \\
\hline
\end{tabular}

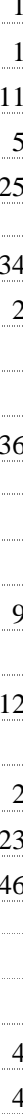

4

8
18

15

9

9
12 $12 / 1$ 15

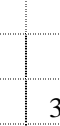

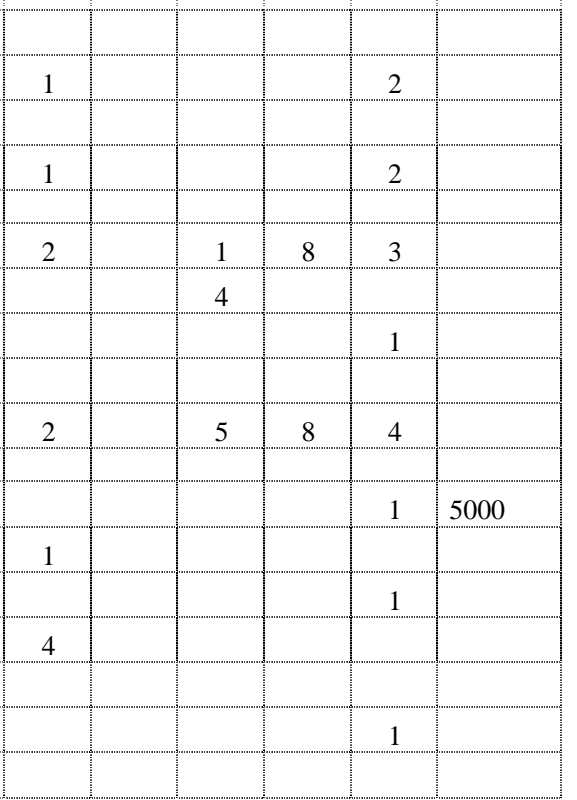

13

26 5
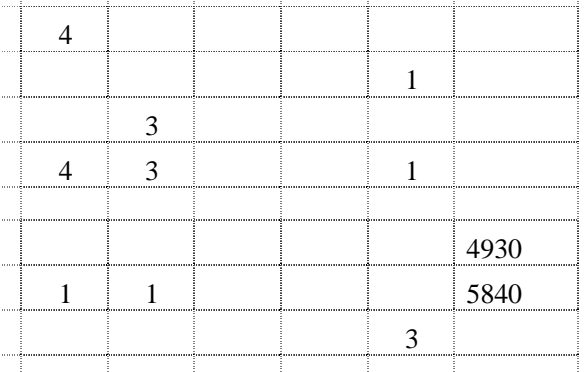
3
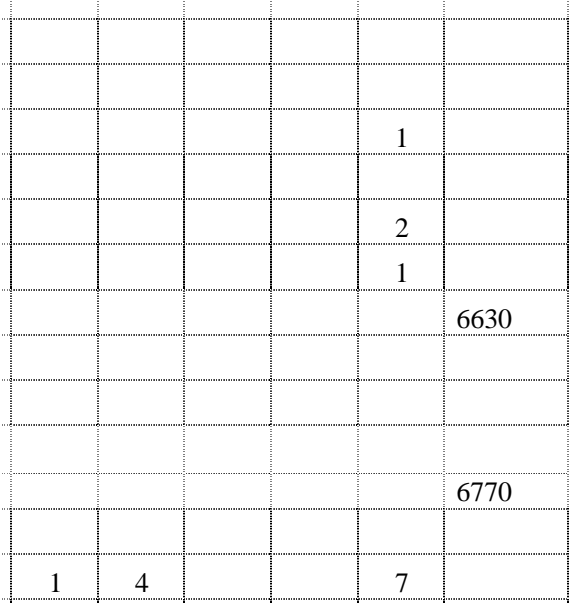
and A. ehrenbergiana. The group "indet" includes mainly vitrified pieces of charcoal in which the wood anatomical structure was not preserved.

Additional to the wood charcoal, an attempt was made to obtain botanical information on some aspects of the paleoeconomy by means of pollen and plant macrofossil analysis of sheep/goat coproliths. From both ME 96/60/154 (AH3) and ME 96/59/83 (AH2), three coprolites were taken and each cluster was treated as a single sample. The material was soaked in distilled water for 24 hours and sieved for macrofossils through a $250 \mu \mathrm{m}$ filter. The filtrate was prepared on standard procedure by treatment with $\mathrm{KOH}, \mathrm{HC}$ and $\mathrm{HF}$ for pollen analysis. The samples were mounted in glycerine and studied under light microscope.

\section{2 - Results}

The wood charcoal analysis of the Tree Shelter site is based on the study of 52 samples with a total number of 436 charcoal fragments, all from $\mathrm{AH} 1$ to $\mathrm{AH} 3$. The results of the analysis are given in table 18 and figure 59. The wood charcoal assemblages from the different archaeological horizons are more or less homogenous in their composition, with a dominance of Acacia and Salvadora persica, but a change in the proportions is noted with an obvious decrease of Salvadora-wood and increased use of the Acacia-wood. In the AH1-2 (the period around or after $3.8 \mathrm{ka}$ calBC (5.0 BP) wood of Ziziphus also appears. The two samples from the oldest level with charcoal preservation (AH4) only yielded unidentifiable, heavily fragmented, wood charcoal material. Looking in the frequency estimations of the main found taxa for the AH1-3 also domination of Acacia and Salvadora persica is visible. The dominance of Salvadora in AH3 seems to be not so significant base on its frequency in the samples, than on number of pieces.

The study of the coprolite samples revealed little identifiable material. Pollen was not preserved, but the macrofossil material showed numerous fragments of wood tissues. In the coprolites from ME 96/60/154 (AH3) small unidentified charcoal particles were available. Such charcoal material usually indicated keeping of the animals in close surrounding of the human occupation (di Lernia 2001)

\section{3 - Reconstruction of the vegetation around the site based on the found wood char- coal assemblages}

The studied wood charcoal gives an idea on the woody vegetation in the surrounding of the site especially during the period covered by the AH1 to AH3 (from $5.6 \mathrm{ka}$ calBC [6.77 ka BP] on ). The material found presents vegetation typical for contracted desert vegetation of wadis and depressions where water accumulation allows growing of perennials with a deep root system (Walter 1990). Representatives of this group are dominating the wood charcoal assemblage, namely Acacia and Salvadora. After 7.0 ka calBC (8 ka BP) more stable conditions with regular and less heavy torrential rains, compared to the Early Holocene, occurred near the site (Moeyersons 1999). This must have allowed, as the wood charcoal analysis shows, the development Acacia stands. The development of the wadi vegetation was a gradual process of accumulation of sediments with ephemeral and partly perennial vegetation, which allowed the creation of a deeply seated, permanently wet-soil layer which underlies an upper layer subject to desiccation in the dry season (Kassas \& Imam 1954, Walter 1990). Finally a stage must have been reached when the deposits became so thick that desert shrubs and trees would have been able to establish themselves (Kassas \& Imam 1954). Such a scenario is also supported by the higher humic content of the valley slopes between 6500-4900 BP (Moeyersons 1999, table 1). At all the stages, the wadi habitat must have been subjected to accidental torrents that may have destroyed the vegetation and washed away the sediments. Usually the central parts of a wadi-bed, probably had no plant cover so the vegetation must have been restricted to the sides, which are usually covered by a perennial plant growth including scrub and open forest types. During the study period most probably stands of Acacia (A. radiana dominating today in the main wadis, A. tortilis and A. ehrenbergiana - the tributaries) and Salvadora developed. The Acacia trees are growing usually on a more coarse sediment (Kassas and Girgis 1970). The modern communities of Salvadora persica are associated with silt terraces of the principal wadis. These silt deposits are usually richer in their salt content $(0,18-0,99 \%$ ) than those of Acacia ehrenbergiana (Kassas and Girgis 1970). Salvadora's abundance in the wood charcoal assemblages from fifth millennium calBC of Makhadma 4 (Vermeersch et al.1992) and third millennium 
calBC from Adaïma (Newton 2005) indicates that its distribution in the region was extensive during the Middle Holocene. The wood charcoal from Maerua crassifolia and Ziziphus might originate from specimens which probably grew as shrubs or as trees in the Acacia-stands. Today only sporadic trees of Salvadora and few specimens of Maerua crassifolia are found in the the area of the Red Sea Hills roughly between the 28-26 $\mathrm{N}$ (Hobbs 1989).

The identifications mentioned by Moeyersons (1999) of wood charcoal from the AH3 from samples given for ${ }^{14} \mathrm{C}$ analysis showed the presence of mainly Acacia-type, Salvadora persica, Cadaba farinosa, Maerua crassifolia, Capparis decidua, and Tamarix sp.. That wood charcoal assemblage resembles quite well the ones documented through the present study.

Tamarix, a taxon that is usually considered as typical for the area (Zahran, Willis 1992), is absent except in the uppermost levels of the site (fig. 59). Similarly, Tamarix is lacking from the Predynastic wood char-

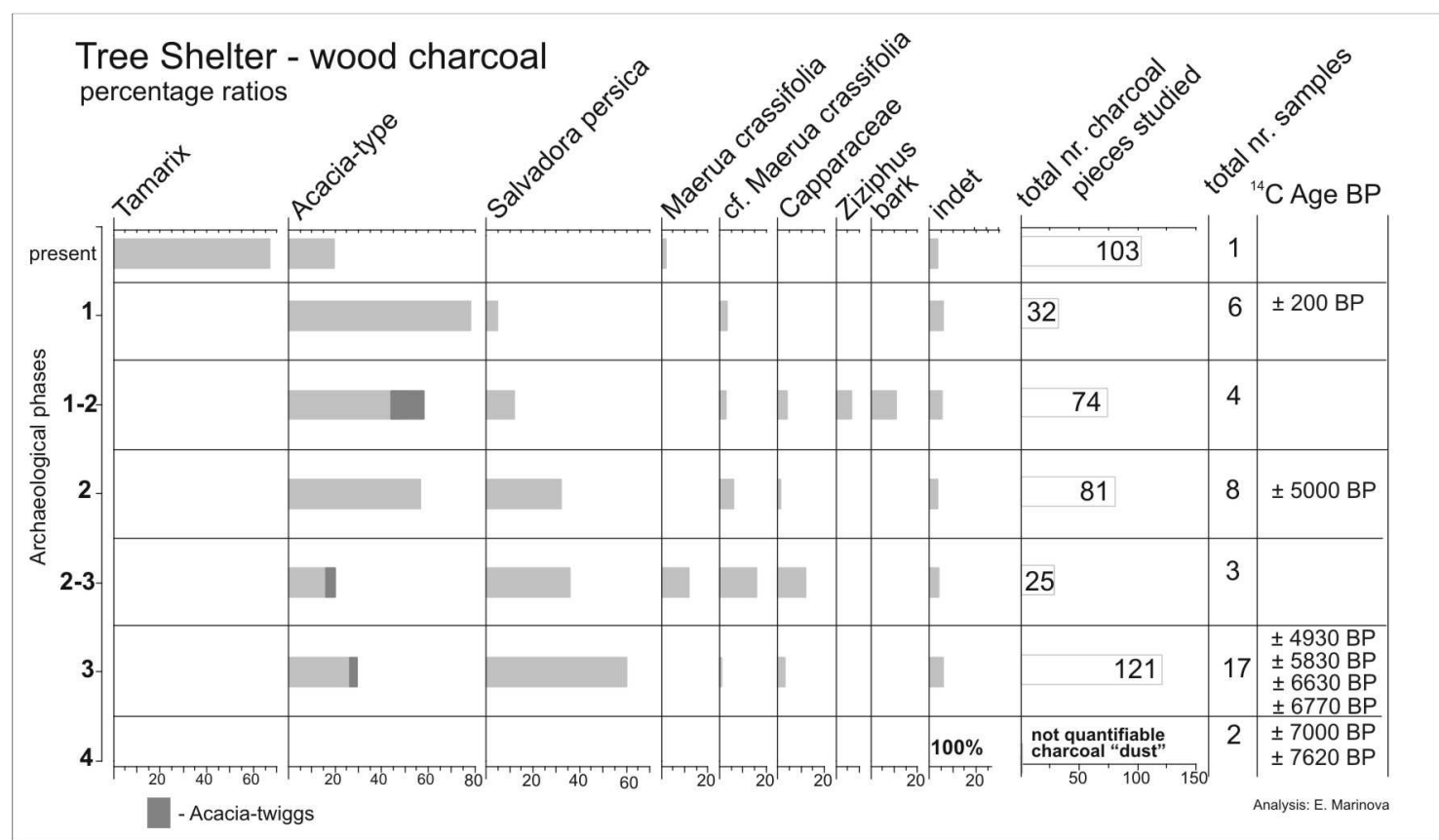

Figure 61 - Wood charcoal assemblage of Tree Shelter in percentage ratios of counted wood fragments

coal assemblages from Makhadma 4 (Vermeersch et al. 1992). This could be connected with the environmental conditions around the site, but also with sampling biases. For the second speak the results of wood charcoal from the AH5, analysed prior to its destruction for ${ }^{14} \mathrm{C}$ dating, which contain some Tamarix fragments (Moeyersons 1999). Another explanation could be connected with the limited availability of Tamarix in the surrounding of the site. Tamarix is predominantly growing in oases and along the Nile river and it only occurs sporadically in rain-fed areas. To the last type areas belongs the vicinity of the site Tree Shelter. Also due to the extreme conditions in the desert the composition of the wadi vegetation is dependent on the available flora in the broad neighbourhood. Wadis as depressions enclosed between 'walls' that are their side cliffs represent habitats with considerable isolation, so that different wadis at comparable stages of development may house vegetation-types different in their floristic composition though similar in their structure, function and dynamics (Kassas 1952). This could be another explanation for the absence of Tamarix in the found Neolithic wood charcoal assemblage.

The anthracological materials from the contemporaneous layers of the nearby cave of Sodmein (ca. 6300 BP) show a similar picture of the wadi vegetation with a predominance of Acacia cf. tortilis, Cadaba farinosa and Salvadora persica (Moeyersons et al. 2002).

The wood charcoal materials available for this study from the earlier AH4 were so badly preserved that no identification was possible. Some idea of the vegetation prior to this periods is given by the wood charcoal analyses from the used for C-14 charcoals from Tree shelter (Moeyerson et al. 1999) wich consist of Tamarix, Acacia-type, Celtis type, Balanites aegyptiaca. From the contemporary layers (7090-7470 BP) of Sodmein cave (Moeyerson et al. 2002) domination of Tamarix was established. In both cases, however, no 
exact quantification of the identifications was provided, which hampers their integration with the new data from Tree Shelter.

On the vegetation history corresponding to the oldest, fifth, layer at the site nothing can be said as no wood charcoal material was identified from it.

\section{4 - What can the wood charcoal assemblages can say on the paleoenvironmental conditions?}

As no wood charcoal data is available from the AH5, no botanical information on the paleoecology about this period could be used. The next AH4 and AH3 from Tree Shelter (Moeyersons et al.1999) and contemporary layers from Sodmen cave (Moeyersons et al. 2002) give a picture quite similar to that established for AH3 by the present study. This is true especially considering the principal composition of the plant taxa found. In the both $\mathrm{AH}(4$ and 3), presence of Sahelian elements (like Salvadora persica and Maerua crassifolia) is observed. The appearance for such kind of vegetation in the Eastern Sahara during the period around 5.9-5.5 ka calBC (7.0-6.5 ka BP) (Neumann 1989) was interpreted as increased precipitation and temperatures in the region. The prevalence of Salvadora persica in the lower part of the diagram (AH3) most probably corresponds to more humid conditions in the area. This small tree is less tolerant to soil drought and is confined to localities where the topographic and climatic conditions offer better supply of moisture and higher temperatures (Kassas and Girgis 1970). These requirements of the plant correspond well with the more humid climatic conditions for the period between 6.9-3.8 ka calBC (8.0-5.0 ka BP) documented by previous studies at Tree Shelter (Moeyersons et al.1999) and at the nearby Sodmein cave (Moeyersons et all 2002), the Red Sea Hills (Butzer 1999) and by regional correlations (Neumann 1989, Hoelzmann et al.2004). The dominance of Salvadora persica in the wood charcoal assemblage from the period 5.6-5.5 ka calBC (6.77-6.63 ka BP) or AH3 is consistent with the sedimentological evidence from the site proving higher frequency of less heavy rains and higher humic content in the valley slopes. Salva-

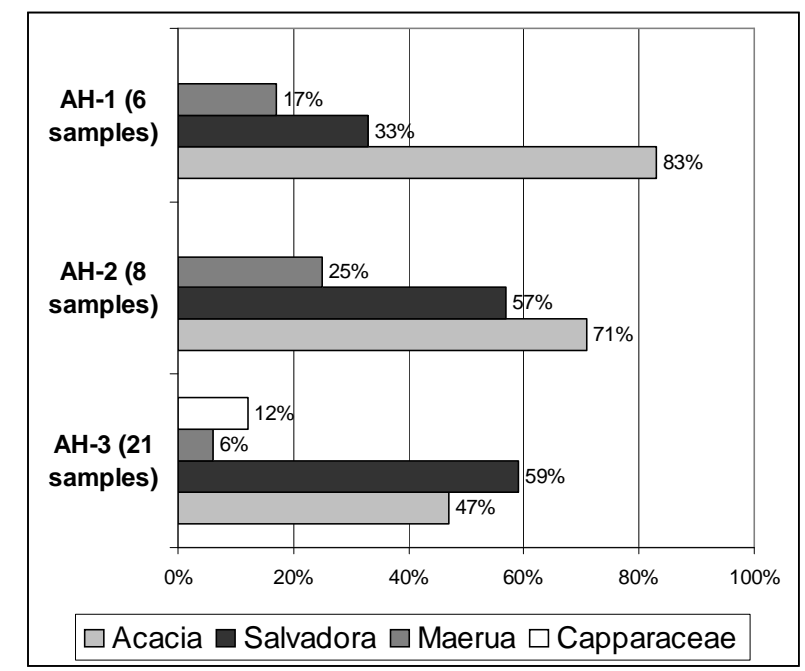

Figure 62 - Frequency (in \%) of the main found taxa in the samples of AH 1-3

dora persica prefers areas where groundwater is readily available for example in seasonally wet sites and along drainage lines in arid zones. The tree is able to tolerate a very dry environment with mean annual rainfall of less than $100 \mathrm{~mm}$. Highly salt tolerant, it can grow on coastal regions and inland saline soil (Kassas and Girgis 1970).

In general the wood charcoal assemblages of the Tree Shelter do not differ greatly trough the indicating more or less stable conditions during the period 5.6-3.7 ka calBC (6.77-4.93 BP). This corresponds well with the broad paleoclimatic estimations for Eastern Sahara (cf. Kuper and Kröpelin 2006). 


\section{5 - Palaeoeconomic implications of the botanical materials studied from the site}

The wadi vegetation, especially Acacia, is attractive for use both as fuel wood and as animal fodder. Most probably the wood charcoal assemblage represents such activities. Acacia tortilis leaves of young trees are eaten by goats and sheep, but the main value of this species is in its pods, which can be very numerous and are picked up from the ground and eaten by all African livestock. At the time when pods are mature, they are often the main source of food for sheep and goats (Briggs et al.1999). Salvadora fruits are sweet and edible. The pulp contains glucose, fructose and sucrose. It is a rich source of calcium containing about 15 times the amount present in wheat (von Maydell 1986). The use of Salvadora as fodder plant at the site is quite plausible too. Leaves and young shoots are browsed by all stock, but normally cattle do not occur in the driest part of the S. persica distribution range and hence it tends to be valued more as a camel, sheep and goat forage. Its leaves make good fodder as their water content is high (15-36\%) (von Maydell 1986).

The decreasing number of Salvadora persica finds during the Neolithic occupation could be connected not only with decreasing humidity, but also with more intense use of the plant as both fuel and fodder. Considering the archaeological evidence for sporadic occupation of the site especially during the earlier AH4 and 5, the more intense Neolithic economy with the presence of domesticated ovicaprine (Vermeersch et al.2002, Linseele, Van Neer this book) may have had a stronger effect on the plant ecosystem. Twigg material in the wood charcoal assemblage and in the ovicaprine coproliths is also a hint in this direction.

Another used plant documented in the wood charcoal material is Ziziphus sp. The presence of Ziziphus spina-christi in Sahara is considered as anthropogenic introduction during the Neolithic, due to its fruits which could be eaten and transported by humans and animals (Barakat 2001). The appearance of Ziziphus sp. in the wood charcoal assemblage of Tree shelter in the final occupation phases of the site (AH1-2) might be indication of such anthropogenic introduction of it.

\section{6 - Conclusion}

The wood charcoal assemblage of the Tree Shelter shows a well developed wadi vegetation with dominance of Acacia and Salvadora persica. Concerning the environment of the site, the botanical evidence corresponds quite well with other sources of palaeoecological information from previous studies and proves more humid conditions than the modern situation. The decrease of Salvadora persica through the AH3-1 could be connected with more intense use of the plant from the Neolithic population as well with increasing aridity through the last 3 occupation phases of the site. Traces of charcoals found in ovicaprine coproliths show domestic animals were kept at the site during the periods covering $\mathrm{AH} 3$ and $\mathrm{AH} 2$. 